\title{
The Time Needed to Rebound after Firms Lost in Litigations: The Role of Information Transparency
}

\author{
Chun-An Li ${ }^{1}$, Ming-Hsi Tang ${ }^{2}$ \& Ying-Cheng Tang ${ }^{1}$ \\ ${ }^{1}$ Department of Finance, National Yunlin University of Science and Technology, Taiwan \\ ${ }^{2}$ Department of Insurance, Chaoyang University of Technology, Taiwan \\ Correspondence: Ming-Hsi Tang, Department of Insurance, Chaoyang University of Technology, 168 Jifeng E. \\ Rd., Wufeng Dist., Taichung City, Taiwan. Tel: 886-4-2332-3000. E-mail: mhtang@cyut.edu.tw
}

Received: December 5, 2014

Accepted: December 20, 2014

Online Published: February 25, 2015

doi:10.5539/ijef.v7n3p157

URL: http://dx.doi.org/10.5539/ijef.v7n3p157

\begin{abstract}
There are abundant researches on the negative effects of litigation. It is acknowledged that litigation can cause wealth leakage when we consider the stock returns of both parties involved. In this study, we use the data of listed electronic and computer-related firms in Taiwan to study the behaviors of long-run abnormal stock returns of the losing firms around the time of litigation judgments and thereafter. We apply event study and threshold regression to examine the existence of long-run abnormal stock returns reversion. Then use OLS to find out factors affecting the length of time needed to reverse the downward trend of abnormal returns. After a period of time, the trends of abnormal stock returns are reversed. The higher level of information transparency the firm is to the market, the faster the reversion occurs. The quality of corporate governance is also negatively correlated to the length of time of reversion.
\end{abstract}

Keywords: inter-firm litigation, event studies, trend reversion, transparency, corporate governance

\section{Introduction}

Due to the well-known phenomena that the American spends a lot of resources in courtrooms in the process of pursuing "justice", inter-firm litigations have engendered considerable interest among academic researchers and a great deal of efforts have been devoted to figuring out the stock market's reaction toward news of litigation. An extensive stream of researches provides evidence on the massive costs related to corporate litigation. Cutlers and Summers (1988) work on an empirical study based on the Pennzoil v. Texaco lawsuit, and confirm the presence of wealth leakage during the process of litigation. The combined wealth of the claimants was reduced by over 3 billion which vanished in thin air. Hertzel and Smith (1993) follow this trail and conclude that the industry portfolio also suffered statistically significant negative effects. This study makes an important contribution by making people notice the collateral damage caused by litigation, either directly or indirectly. Other researchers (Bhagat, Bizjak, \& Coles, 1998; Koku, Qureshi, \& Akhigbe, 2001; Afik, Lahav, \& Ochakovski, 2014) also acquire similar conclusions under a more generalized scenario while elaborating the study on the topic of litigation from different perspectives.

Bhagat et al. (1998) examine the stock market reaction at two extinct points of time: litigation filing and settlement announcement. They analyze a sample of 355 observations collected from 1981 to 1983 and find factors relating to the explanation of diversified degree of wealth loss due to litigation. Koku et al. (2001) on the other hand, focus on the disparity of market reactions according to the characteristics of the lawsuits and the parties involved. Afik et al. (2014) provide interesting observation in the Israel market where the market scale is relatively small compared to previous studies. This motivates us to conduct a research based on local market data and hope to offer some insights to investors in developing countries like Taiwan. Considering the fact that the electronic and computer-related industry comprises about $70 \%$ of this country' export trade. This study focuses on the listed firms in the electronic and computer-related industry in Taiwan.

When it comes to the aftershock of litigation, Autore, Hutton, Peterson, and Smith (2014) study the effect of securities litigation on external financing. They use a comprehensive sample and find that the likelihood of external debt and equity financing is remote when firms involved in severe litigation. Thus leads to the shrinkage in capital expenditures and research and development following a litigation filling. In many firms, one of the 
most important financial decisions made by management executives is to determine how much the firm should spend in research and development (R\&D). Generally speaking, R\&D investment is beneficial to the firm's long-term development. Therefore, when a firm cuts back on these expenditures, its future doesn't look very bright from where the investors stand. Perhaps that's the reason why corporate misconduct can decrease reported earnings and earnings forecasts as documented in Murphy, Shrieves, and Tibbs (2009). Corporate misconducts also raise the firm's risk such as stock return volatility and analyst forecast divergence. To further investigate the adverse effects litigation has on firms, we concentrate our study on the defeated party in litigation. We employ an event study methodology (Brown \& Warner, 1985; MacKinlay, 1997; Campbell, 1997) to calculate the long-run abnormal stock returns of the losing firms around the time of litigation judgments and thereafter.

We noticed that the average cumulative abnormal returns seem to exhibit a trend reversion in several researches (Farber, 2005; Karpoff, Lee, \& Martin, 2008; Afik et al., 2014). Marciukaityte, Szewczyk, Uzun, and Varma (2006) find that companies increase the proportion of outsider directors on their boards of directors and on the monitoring committees of the boards after being charged of misconduct. The effort to restore trust by improving the firm's corporate governance is apparent. Also, they present comparable long-run stock price and operating performance between companies charged with misconduct and a matching controlled sample. These results suggest that corporate governance does matter when it comes to rebound from a setback.

This study applies the methodologies used in previous researches to evaluate whether the market reaction concerning litigation is different in a small market like Taiwan. We then focuses on identifying the factors affecting the length of time required for losing firms' abnormal returns to change the direction of their movement. What is unique in this study is that we introduce two well-developed variables as proxies for information transparency and corporate governance (Chen, Kao, Tsao, \& Wu, 2007) which are not used in previous studies relating to inter-firm litigations. These two variables are computed based on data from local database and turn out to be indicative and informative. This study confirms that the losing firms' movement of abnormal returns will change after a period of time. The trends of abnormal stock returns are reversed. The level of information transparency and quality of corporate governance plays an important role to the length of time of reversion.

The rest of this study proceeds as follows: Section 2 presents the data and variable construction, Section 3 describes the methodology, Section 4 presents analysis and discussion and we conclude in section 5 .

\section{Data and Variable Construction}

In order to observe the trend reversion of long term abnormal returns, we select the firms that lost inter-firm lawsuits between 2005 and 2010, thus provides the longer window required in this study. The winning or losing litigation is based on the judgment. If the judgment is in favor of the other party, we conclude the firm loses the litigation. Therefore, if firms settle outside the court, they won't be included in our sample. To further concentrate the focal point in this study, the firms in the electronic and computer-related industry are chosen as they comprise more than $50 \%$ of total stock market value in Taiwan. Therefore, these firms are vital to Taiwan's economic development and worth exploring. When selecting our sample, we deliberately excluded firms in other industries to avoid the confound effects that might arise from characteristics that are unique to each industry. Table 1 shows the filtering process under these criteria. A total of 415 listed corporations in Taiwan are involved in inter-firm litigation during 2005 to 2010. Out of which, 185 judgments are announced and 50 firms in the electronic and computer-related industry lost.

Table 1. Sample selection process

\begin{tabular}{cccc}
\hline Year & $\begin{array}{c}\text { Firms involved in inter-firm } \\
\text { litigations }\end{array}$ & $\begin{array}{c}\text { Litigation judgments } \\
\text { announced }\end{array}$ & $\begin{array}{c}\text { Firms lost litigations in } \\
\text { targeted industry }\end{array}$ \\
\hline 2005 & 35 & 20 & 7 \\
2006 & 61 & 33 & 8 \\
2007 & 74 & 43 & 9 \\
2008 & 88 & 27 & 9 \\
2009 & 80 & 32 & 7 \\
2010 & 77 & 30 & 10 \\
Total & 415 & 185 & 50 \\
\hline
\end{tabular}

We then collect financial data on all variables that are used in estimation from Taiwan Economic Journal (TEJ), which is the source of public firm announcements and data in Taiwan. TEJ was founded in April 1990 in Taiwan. 
It aims to provide in-depth and extensive historical financial data, and information in the major financial markets in Asia with high quality. To calculate the long-run abnormal stock returns of the losing firms around the time of litigation judgments and thereafter, this study gathered data from 2005 to 2013. In other word, we collect 3-year return data after firms lost in litigations.

As for transparency and information disclosure, we use the annual evaluation report conducted by Taiwan's Securities and Futures Institute (SFI): "Information Disclosure and Transparency Ranking Results in Taiwan" to construct the proxy variable TRA we need. Although several leading financial information providers have launched disclosure rankings and evaluations, the evaluation criteria chose by those institutions might not offer an overall evaluation of disclosure practices in local markets as Taiwan. To respond to the calls for standard setters and regulators to develop disclosure requirements consistent with international standards, the SFI has launched "Information Disclosure and Transparency Rankings System" (IDtrs) to assess the level of transparency for all listed companies in Taiwan since 2003. We convert the qualitative ranking used in "IDtrs" into a 5 point scale to better serve purpose.

"Corporate Governance Index" (CGI) are built for each firm based on Chen et al. (2007). CGI is comprised of four different aspects of the company's governance mechanism: 1. CEO duality, 2. size of the board of directors, 3. managements' holdings and 4. block shareholders' holding. Chen et al. (2007) find that CGI is successful in evaluating the effectiveness of the governance mechanism of firms in Taiwan. We will construct the CGI for each firm of interest, and use this index as a proxy variable to represent the effectiveness of the corporate governance structure. Table 2 presents the variables constructed in this study and their definitions.

Table 2. Variables and definitions

\begin{tabular}{ll}
\hline Variables & Definitions \\
\hline CEO duality & Chief Executive Officer also serves as the Chairperson of the Board. \\
Size of the board of directors & Number of directors on the board. \\
Managements' holdings & The fraction of shares owned by the top five largest shareholders. \\
Block shareholders' holding & Indicator equals 1 if total ownership of all block shareholders larger than 25\%, 0 otherwise. \\
CGI & CEO duality+ Size of the board of directors + Managements' holdings + Block shareholders' holding \\
TRA & Proxy for transparency and information disclosure, converted from IDtrs. \\
\hline
\end{tabular}

\section{Methodology}

This study analyze the market reaction toward the publicly listed corporations in specified industries that lost in litigation in Taiwan around the time of litigation judgment in the years 2005-2010 using event study methodology. Event study analysis tests effects on stock returns to observe the influence of new information (Fama, Fisher, Jensen, \& Roll, 1969). This approach has been used extensively for a wide range of issues to identify the timing and magnitude of market reaction when unexpected event occurs. The market model is based on the argument that the expected returns of the examined firms and those of a benchmark market portfolio are linear. Such that

where

$$
R_{i, t}=\alpha_{i}+\beta_{i} R_{m, t}+\varepsilon_{i, t}
$$

$R_{i t}=$ return on firm $\mathrm{i}$ at week $\mathrm{t}$;

$R_{m t}=$ return on the market portfolio at week t;

$\varepsilon_{i t}=$ residuals

We estimated the parameters of Eq. (1) using ordinary least square (OLS) regression in the window $t \in[-180,-31]$. And apply our estimations $\left(\hat{\alpha}_{i}\right.$ and $\left.\hat{\beta}_{i}\right)$ to calculate the abnormal returns such that

$$
\mathrm{AR}_{i, t}=R_{i, t}-\left(\hat{\alpha}_{i}+\hat{\beta}_{i} R_{m, t}\right)
$$

in the window $t \in[-2,180]$. The sign and magnitudes of abnormal returns are served as indicators of market's reaction toward new, unexpected information (Brown \& Warner, 1985). We next compute the cumulative abnormal returns (CAR) and average cumulative abnormal returns (ACAR) for the period of interest.

$$
\mathrm{CAR}_{i}=\sum A R_{i, t}
$$




$$
\operatorname{ACAR}_{i}=\frac{1}{\mathrm{~N}} \sum A R_{i, t}
$$

Average cumulative abnormal returns are calculated under the assumption that the litigation events and their outcomes of different firms in our sample are independent. We examine the evolution of ACAR by observing the pattern of its movement. Then we apply the threshold regression to identify the existence of trend reversion. When conducting event study, prior researchers rarely apply a long window as ours. However, the seemingly long observation period suits our purpose of detecting the trend reversion of abnormal stock returns. Lyon, Barber, and Tsai (1999) tests for long-run abnormal returns and support that two methods yield well-specified test statistics in random samples. The underlying distribution used for inference is based on either a skewness-adjusted " $t$ "-statistic or the empirically generated distribution of long-run abnormal returns. Following their framework, we obtain the ACARs, and utilize threshold regression (Hansen, 2000) to identify the existence of trend reversion using:

$$
\operatorname{ACAR}_{t}=c+\theta_{t}+d D_{t}(\gamma)+\delta_{1} t \times D_{t}(\gamma)+\varepsilon_{t}
$$

Where $\gamma$ is the threshold value, and $D_{t}(\gamma)=1$, when $t \leq \gamma$, otherwise $D_{t}(\gamma)=0$.

To examine the factors affecting the length of time required for losing firms to alter the direction of movement of their abnormal returns, we conduct several ordinary least square equations to take a closer look at the relationships between the reversion time and the concerned variables. We choose the related corporate governance variables following Chen et al. (2007). Considering the database collected in Taiwan and market characteristics, Chen et al. (2007) find that CGI is successful in evaluating the effectiveness of the governance mechanism of firms in Taiwan. Farber (2005) uses a sample of 87 firms that are identified by SEC as fraudulently manipulating their financial statements, and unveils the positive association of corporate governance and stock performance. Therefore, we think the relationship between corporate governance and the abnormal return of the firms lost in litigations is also positive. Here we construct a hypothesis:

\section{Hypothesis: More transparent and better-governed firms will recover from defeats faster.}

In order to test the hypothesis, we build the following equations:

$$
\begin{gathered}
\mathrm{Y}=\alpha_{i}+\beta_{1, i} T R A+\beta_{2, i} C G I+\varepsilon_{i} \\
\mathrm{Y}=\alpha_{i}+\beta_{1, i} T R A+\beta_{2, i} B I+\beta_{3, i} B S H I+\beta_{4, i} C E O I+\beta_{5, i} M O I+\varepsilon_{i} \\
\mathrm{Y}=\alpha_{i}+\beta_{1, i} T R A+\beta_{2, i} \mathrm{DIR}+\beta_{3, i} D \mathrm{R}+\beta_{4, i} \mathrm{ROA}+\beta_{5, i} \mathrm{IPM}+\beta_{6, i} \mathrm{CGI}+\varepsilon_{i} \\
\mathrm{Y}=\alpha_{i}+\beta_{1, i} T R A+\beta_{2, i} \mathrm{DIR}+\beta_{3, i} \mathrm{DR}+\beta_{4, i} \mathrm{ROA}+\beta_{5, i} \mathrm{IPM}+\beta_{6, i} B I+\beta_{7, i} B S H I+\beta_{8, i} C E O I+\beta_{9, i} M O I+\varepsilon_{i}
\end{gathered}
$$

$\mathrm{Y}$ is the threshold values of abnormal return trend reversion for each firm.

\section{Analysis and Discussion}

Figure 1 exhibits the evolution of the ACAR of the firms in our sample in the period $[-3,180]$ using the market model. Consistent with prior research, results indicate that the ACAR of firms lost in litigations are negative post the judgment announcement (Bhagat et al., 1998; Koku et al., 2001; Cutler \& Summers, 1988; Hertzel \& Smith, 1993; Murphy et al., 2009; Afik et al., 2014). Losing the lawsuits is undoubtedly bad news from the investors' perspectives. The occurrence of significantly negative abnormal returns suggests new, unanticipated bad news. The graph conforms to our anticipation of observing a downward trend of abnormal returns. When the litigation judgment is announced, the abnormal returns of the losing firms take a rapid slump and keep descending. However, when we take a closer look, the behaviors of ACAR appears to exhibit dissimilar characteristics between different intervals in our sample. After a period of time, the losing firms seemed manage to shed off the influence of the litigation judgment and put a stop to the disappointing fall. Figure 1 can perfectly justify our use of a longer event window in this study for it suffices to reveal the trend reversion. If we adopt a short observation window, we would not be able to discover the alternation of movement that occurred in the far right end.

To evaluate whether the observed pattern of ACAR is statistically significant, we apply threshold regression to detect the possible change of structure. A threshold model is a model where a threshold value, or set of threshold values, is used to distinguish ranges of values where the behavior predicted by the model varies in some important way. The Chow test is used to test for the presence of a structural break. The result from threshold regression is displayed in Table 3. For the losing firms, the behavior of their ACAR does show a structural change. The threshold value is 117 with a statistically significant p-value of 0.000062 . It is clear now that the ACAR of the defeated firms in litigation does suffer from market overreaction since it exhibit trend reversion. 


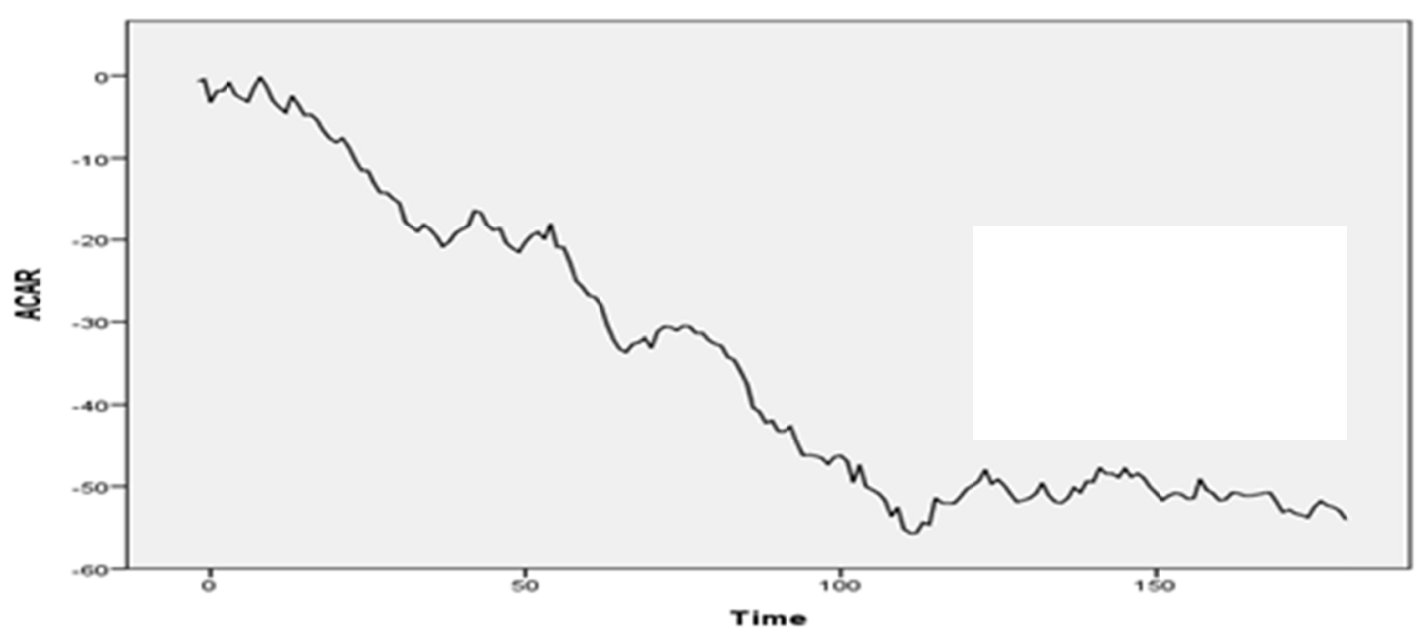

Figure 1. A graph of the market's reaction toward litigation judgments of the losing firms

Table 3. Threshold estimation

\begin{tabular}{ll}
\hline Threshold Variable $=$ & Time \\
\hline Threshold Estimate: & 117 \\
.95 Confidence Interval: & {$[101.00,119.00]$} \\
Sum of Squared Errors & 869.754174 \\
Residual Variance: & 4.858962 \\
Joint R-Squared: & 0.985051 \\
Heteroskedasticity Test (p-value): & 0.000062 \\
\hline
\end{tabular}

After confirming the existence of threshold value and structural change of abnormal returns' trend, we move on to analyze the factors that might have effects on the time needed to reverse or alleviate the downward trend of abnormal returns. The threshold values of abnormal return trend reversion for each firm are calculated and assigned as variable Y. Table 4 provides summary statistics of all the variables used in subsequent estimations. In table 4, we present the descriptive statistics of the variables that will be used in the OLS regression for the full sample. The shortest time needed for a losing firm to recover is 22 weeks, and the longest is 183 weeks. The factors that cause such substantial discrepancy are surely worth exploring.

It is commonly agreed that better corporate governance is related to better firm performance, thus better-governed firms are supposed to perform better than worse-governed firms. Therefore, we introduced variables that are frequently used in estimations such as number of members in board of directors (DIR), debt ratio (DR), return on equity (ROA) and interest protect multiples (IPM) into our analysis to examine these variables' influence on the dependent variable Y. Before we proceed to OLS regression estimation, we perform collinearity diagnostics to avoid the undesirable situation where the correlations among the independent variables are strong. We omit the presentation here for the purpose of brevity and no two variables have correlation coefficients larger than 0.8 .

Table 4. Summary statistics of variables (the number of observation is 50)

\begin{tabular}{lccccccccccc}
\hline & Y & TRA & DIR & DR & ROA & IPM & MOI & BSHI & BI & CEOI & CGI \\
\hline $\max$ & 183 & 5 & 11 & 87.95 & 61.66 & 665.15 & 1 & 1 & 1 & 1 & 4 \\
$\min$ & 22 & 3 & 5 & 16.98 & $(14.45)$ & $(80.61)$ & 0 & 0 & 0 & 0 & 1 \\
average & 90.76 & 3.92 & 7.44 & 51.61 & 7.78 & 71.44 & 0.74 & 0.62 & 0.90 & 0.26 & 2.52 \\
Std. dev. & 31.12 & 0.83 & 1.74 & 15.96 & 18.17 & 156.75 & 0.44 & 0.49 & 0.30 & 0.44 & 0.95 \\
\hline
\end{tabular}

As we disclosed above, the time needed for those corporations which were defeated in litigations to come back is vastly diverse. In order to identify the factors that are of importance, we introduce two variables that are unique in this study: TRA and CGI. TRA is a proxy variable we construct to represent corporate transparency and information disclosure. CGI is used as a proxy for corporate governance and has been empirically proven to be 
able to successfully evaluate the effectiveness of the governance mechanism of firms in Taiwan. Therefore, the inclusion of these two variables into our study can better identify the firms' characteristics. In Table 5, we investigate the effects of independent variables on the length of time needed for a losing firm's abnormal return to reverse the downward trend.

In model 1, we can see that TRA and CGI are negatively related to variable Y and the estimations are both statistically significant. The result conforms to our hypothesis. According to model 1, the higher the level of information transparency the firm is to the market, the faster the reversion occurs and the better the quality of corporate governance is, the shorter the length of time of reversion. In model 2, we break down the CGI index into the four different aspects of the company's governance mechanism to examine the individual effect. It turns out that CEOI (Chief Executive Officer also serves as the Chairperson of the Board) and MOI (the fraction of shares owned by the top five largest shareholders) are two influential variables and the estimations are both negative. We introduce 4 variables that commonly used to represent corporate governance and performance into model 3. Although CGI is no longer statistically significant in this model, TRA remains a prominent variable in deciding market reaction toward firms. It is also very interesting to find that debt ratio is positively related to variable Y. This is intuitive because a firm deep in debt is not going to be out of red very soon. In our final model, we are pleased to see after putting all the variables into the regression analysis, TRA maintain to be statistically significant.

Table 5. The effect of TRA and CGI on the time reverse the trend



Note. Significance at the $10 \%, 5 \%$ and $1 \%$ levels is denoted by $*, * *$ and $* * *$, respectively.

\section{Conclusion}

This study first employs market model to estimate the firms' pre-litigation judgment expected returns. The empirical results are coherent to previous studies and exhibit a disappointing downward trend as expected. Then we apply event study methodology to examine the effect of negative judgments on firms. After confirming the existence of trend reversion, we identify the variables that are important in affecting the time needed to reverse the disappointing downward spiral. Existing literatures might have investigated the short term reactions of investors toward firms with bad news, however, few addresses the long term performance as proposed in this study. We find that information transparency is a crucial factor. When the information asymmetry is not an issue among investors, they are more likely to accredit the firm through stock returns. Corporate governance, especially the role CEO plays and the fraction of shares owned by the top five largest shareholders, is also noteworthy. 
The empirical results from this study can serve as evidence for the merits of higher information transparency and better corporate governance. Therefore, we propose that government authority should enact related regulations or guidelines to help the firms in Taiwan to be more in line with firms in developed markets. We believe this study has broadened the researches on inter-firm litigation. To append current researches, we identify the factors affecting the length of time required for losing firms to alter the direction of movement of their abnormal returns. This study can serve as a bridge connecting the researches on litigation and those on the topic of information transparency and corporate governance.

\section{References}

Afik, Z., Lahav, I., \& Ochakovski, Z. (2014). There's no smoke without fire: equity returns response to indictment filing. International Journal of Economics and Finance, 6(7), 24-30. http://dx.doi.org/10.5539/ijef.v6n7p24

Autore, D. M., Hutton, I., Peterson, D. R., \& Smith, A. H. (2014). The Effect of Securities Litigation on External Financing. Journal of Corporate Finance, 27, 231-250. http://dx.doi.org/10.1016/j.jcorpfin.2014.05.007

Bhagat, S., Bizjak, J., \& Coles, J. L. (1998). The shareholder wealth implications of corporate lawsuits. Financial Management, 27(4), 5-27. http://dx.doi.org/10.2307/3666410

Brown, S. J., \& Warner, J. B. (1985). Using Daily Stock Returns: The Case of Event Studies. Journal of Financial Economics, 14(1), 3-31.

Campbell, J., Lo, A., MacKinlay, C., \& Whitelaw, R. F. (1997). The Econometrics of Financial Markets. Princeton, NJ: Princeton University Press. http://dx.doi.org/10.1017/S1365100598009092

Chen, A., Kao, L., Tsao, M., \& Wu, C. (2007). Building a Corporate Governance Index from the Perspectives of Ownership and Leadership for Firms in Taiwan. Corporate Governance: An International Review, 15(2), 251-261. http://dx.doi.org/10.1111/j.1467-8683.2007.00572.x

Cutler, D., \& Summers, L. (1988). The cost of conflict resolution of financial distress: Evidence from the Texaco-Pennzoil litigation. The Rand Journal of Economics, 19(2), 157-172. http://dx.doi.org/10.2307/2555697

Fama, E. F., Fisher, L., Jensen, M. C., \& Roll, R. (1969). The adjustment of stock prices to new information. International Economic Review, 10(1), 1-21. http://dx.doi.org/10.2307/2525569

Farber, D. B. (2005). Restoring trust after fraud: does corporate governance matter? The Accounting Review, 80, 539-561. http://dx.doi.org/10.2308/accr.2005.80.2.539

Hansen, B. E. (2000). Sample splitting and threshold estimation. Econometrica, 68(3), 575-603. http://dx.doi.org/10.1111/1468-0262.00124

Hertzel, M. G., \& Smith, J. K. (1993). Industry effects and interfirm lawsuits: Evidence from Pennzoil v Texaco. The Journal of Law, Economics, \& Organization, 9, 425-444.

Karpoff, J. M., Lee, D. S., \& Martin, G. S. (2008). The cost to firms of cooking the books. Journal of Financial and Quantitative Analysis , 43, 581-611. http://dx.doi.org/10.1017/S0022109000004221

Koku, P. S., Qureshi, A. A., \& Akhigbe, A. (2001). The Effects of News on Initial Corporate Lawsuits. Journal of Business Research, 53(1), 49-55. http://dx.doi.org/10.1016/S0148-2963(00)00184-3

Lyon, J. D., Barber, B. M., \& Tsai, C. (1999). Improved methods for tests of long-run abnormal stock returns. The Journal of Finance, 54(1), 165-201. http://dx.doi.org/10.1111/0022-1082.00101

MacKinlay, A. C. (1997). Event studies in economics and finance. Journal of Economic Literature, 35(1), 13-39.

Marciukaityte, D., Szewczyk, S. H., Uzun, H., \& Varma, R. (2006). Governance and performance changes after accusations of corporate fraud. Financial Analysts Journal, 62, 32-41. http://dx.doi.org/10.2469/faj.v62.n3.4155

Murphy, D. L., Shrieves, R. E., \& Tibbs, S. L. (2009). Understanding the penalties associated with corporate misconduct: An empirical examination of earnings and risk. Journal of Financial and Quantitative Analysis, 44(1), 55-83. http://dx.doi.org/10.1017/S0022109009090036

Raghu, T. S., Woo, W., Mohan, S. B., \& Rao, H. R. (2008). Market reaction to patent infringement litigations in the information technology industry. Information Systems Frontiers, 10(1), 61-75. http://dx.doi.org/10.1007/s10796-007-9036-5 


\section{Copyrights}

Copyright for this article is retained by the author(s), with first publication rights granted to the journal.

This is an open-access article distributed under the terms and conditions of the Creative Commons Attribution license (http://creativecommons.org/licenses/by/3.0/). 